\title{
Assessment of Nanomaterials Use in Asphalt
}

\author{
Khalil Tabatabaie $^{1 *}$, FarhadTabatabaie $^{2}$

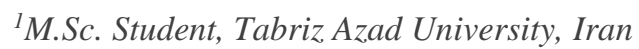 \\ ${ }^{2}$ M.Sc. Student, Urmia University, Sazeh, Iran
}

*Corresponding Author: Khalil Tabatabaie, M.Sc. Student, Tabriz Azad University, Iran

\begin{abstract}
This article reviews the advances of using nanomaterials in hot mix asphalt. Clay nanoparticles are raw materials used in the manufacture of asphalt. Adding nanoparticles such as nanoparticles, nanosilica and nanotubes to asphalt typically increases the viscosity of asphalt binders and improves the wear and tear resistance of asphalt mixtures. Using nanoclay as a second modifier in polymer modified asphalt can improve storage stability and aging resistance of polymer modified asphalt. Nanotechnology has gradually infiltrated the asphalt industry. It now appears that the magical effects of nanomaterials have been proposed to improve asphalt performance. To illustrate many prospective applications, researchers have undertaken a series of positive and effective measures in preparing modified asphalt to demonstrate the modification mechanism and improve the result of its performance. In this study, first, different nanomaterials used in asphalt modification are presented, and then the methods used in asphalt modification with these materials and finally the impact of nanomaterials on basic asphalt performance and modification mechanisms are discussed.
\end{abstract}

Keywords: Asphalt mix, Nanotechnology, Nanomaterials, Additives, Technology.

\section{INTRODUCTION}

In general, bitumen plays a pivotal role in sidewalks, and flexible coatings have often been studied by scientists because of poor performance. Also, they often try to improve their performance by increasing the material.

Nanotechnology has been extensively studied to address problems in the design, fabrication and use of functional structures with at least one characteristic dimension per nanometer [13]. The US National Nanotechnology Initiative states that nanotechnology involves the research and development of technology at the atomic, molecular or macromolecular level, with a length scale of approximately 1 to 100 Is nanometer (nanometer) to provide a basic understanding of the phenomena and materials in nanotechnology. Scale and create and use structures, devices, and systems that have new properties and functions due to their small or intermediate size [18].

Therefore, nanotechnology enables the design of systems with high performance density, high sensitivity, surface-specific effects, large surface area, high pressure resistance and catalytic effects. All properties are directly or indirectly derived from the small size of the nanoparticles [26].

Although bitumen materials such as asphalt are mainly used on a large scale and in large quantities for road construction, the macroscopic mechanical behavior of these materials still largely depends on the microstructure and physical properties of the micro [20]. Although researchers, material manufacturers and engineers have explored this potential for many years, the use of nanotechnology has been limited. New and exploratory efforts are underway to develop nanomaterials for pavement application that will improve the mechanical and physical properties of the nanoscale as well as the durability of this important group of building materials. Therefore, nanotechnology enables the design of systems with high performance density, high sensitivity, surface-specific effects, large surface area, high pressure resistance and catalytic effects. All properties are directly or indirectly derived from the small size of the nanoparticles [26].

\section{BACKGROUND}

The research worth mentioning is the work done by Ghile in the Netherlands. Ghile's work focuses on microscopic analysis of nano- and nano-cholecystitis. Among the cases in this microscopic study is 
the scientific fact that nano-clays have very large ratios. In addition, nanoclay is usually uniform in size and layout and appears to be larger and less curly than the nanoclay. The $6 \%$ illegal inlet rate of an asphalt bond causes permanent deformation or decay behavior of the asphalt bond system and increases pyrisento resistance in both the aging and long-term (oxidation) periods of the asphalt bond system. In both the designed asphalt bonding system and the paving blend, nano-metal and nanocatalysts have less fatigue resistance than unmodified asphalt bonds and mixtures. The effect of nanomaterials as much as underwater asphalt mixtures or antifreeze solutions has recently been investigated. The sensitivity and humidity of humidity and desalting effects were investigated by placing the samples in chemicals in water or freezing $(\mathrm{NaCl}, \mathrm{MgCl} 2$ and $\mathrm{CaCl} 2)$ and seven freezethaw cycles. It was found that the addition of nanoclay and micro-carbon increased the moisture sensitivity of a mixture in most cases [6]. Tanzadeh et al. (2013) conducted a study to evaluate the effect of nano-TiO2 on improving asphalt bond adhesion and caries resistance in asphalt-coated under load. For this purpose, wheel tracking experiments were performed on hot mixed asphalt (HMA) hot and nano-TiO2-modi carried samples. The results show that the use of nano-TiO2 in asphalt bond samples increases the depth of routing compared to conventional mixtures [28].

\section{Asphalt}

The sidewalks are a combination of layers of engineered materials that generally provide all air access to vehicles for travel in a safe and economical way. The layers of materials used are selected and engineered to withstand a structure that can withstand the loads of vehicles applied to a wide range of environmental conditions for a defined minimum life. Typically, deeper materials in pavement structures are less affected by vehicle loads and environmental changes, while pavement components are directly exposed to the environment (daily and seasonal changes), and Also loads of functional vehicles. The purpose of good asphalt design is to enable vehicles to travel safely and economically. A typical sidewalk consists of 5 special layers. The substrate, selective, and substrate layers are usually composed of granular material, while the substrate can be a finite or unlimited granular material. Bordered granular base layers can usually be engineered using cement or bitumen. The pavement surface is usually made of bitumen or cement. These can consist of surface seals (a layer of aggregate that binds to a layer of bitumen, asphalt (a mixture of aggregate, filler and bitumen) or concrete (a mixture of aggregate, filler and cement). [27].

\section{INTRODUCING NANO MATERIALS}

The materials are morphologically characteristic at the nanoscale, and in particular have specific properties due to their nanoparticle dimensions [29]. Since high performance polyamide clay nanocomposites have been developed by Toyota Research Center, polymer grade nanocomposites have been the subject of special interest in academia and industry due to their unique mechanical, thermal, barrier, optical, electrical and magnetic properties [30]. [9]. Focused material science and technology research is the material consisting of macrotromicronoruscule. Ingredients are varieties of varieties, liquid, semi-solid solid, a complex mixture of Yazablocardar asphalt containing hydrocarbons of different molecular weight and non-metallic derivatives. Asphalt is commonly used as an organic bonding material for waterproofing, moisture resistance and corrosion protection [10] [11]. There are various types of asphalt modifications, including various resins, tires, polymers, sulfur, metal complexes, negatives, and chemicals [34].

The main objectives of this research are as follows:. Investigating the Effect of Nanoparticles on the Rheological Properties of Asphalt Bonding. Investigation of the rotation of asphalt samples prepared by modified asphalt substrate with $4 \%$ specific value of nanoparticles and. Homogeneous investigation of nanoparticle distribution in asphalt bonds [31].

\section{AdVANTAGES OF NANOTECHNOLOGY IN ASPHALt COMPOSITES}

The advantages of using modified asphalt joints are widely recognized as being primarily resistance to rotation, reduced cracking and reduced cold air cracking. These improvements in performance, durability, and life cycle cost savings, compared to unmodified pavements, have led to widespread use of modified pavements. There are alternatives as potential modifiers. Reasons for evaluating new materials include improving performance, reducing waste disposal costs, and reducing the cost of modified additives. 
- Nanotechnology has the following known benefits:

- Storage stability in polymer modified asphalt

- Increase resistance to UV aging

- Reduce the sensitivity to moisture under water, snow and ponds

- Improve the properties of asphalt mixtures at low temperatures

- Improves durability of asphalt

- Save energy and cost

- Reduce maintenance needs [14]

\section{NANOTECHNOLOGY APPLICATIONS}

Nanotechnology has various applications in the asphalt industry, including:

- Asphalt surface protection against sunlight.

- Waterproof and freezing coating of asphalt surface;

- Making non-stick surface for easier control of asphalt mix steam.

- Adhesion of two layers of asphalt.

- Adhesion of asphalt layer to non-asphalt layer.

- Cavity and cavity cracks.

- Better adhesion of materials to each other.

- Formation of nanocapsules containing asphalt adhesive modifiers.

- Reduce the effects of asphalt bond aging on asphalt mixtures.

- Used as a rejuvenating substance.

Also, nanoparticles protect the asphalt bond from oxidation by extending the air flow path [5]. Therefore, the nanoparticles affect the macroscopic properties by changing the asphalt bond.

\section{Quantitative STUdies OF ASPhalt NanOPARTICleS}

Few studies have been performed on nanoparticles in the asphalt coating industry [24]. Nanotechnology is predicted to provide great potential for the development of the asphalt coating industry in materials design, manufacturing, properties, testing, monitoring and modeling halls [2]. Performed molecular simulations to evaluate the self-repair of asphalt bond bond cracks in asphalt mixtures. These simulations are focused on determining the energy density of a set of molecules under different conditions. Self-dispersive analysis of concrete reinforced concrete molecules showed that there is a good relationship between molecular chain length and branching of molecules to selfdispersion of molecules at the crack interface and consequently to their self-repairing bonding properties. This is an example of the use of molecular analysis in describing a problem of macrolytic asphalt [15]. He described a new program in which repair with $\mathrm{TiO} 2$ was investigated as an ultraviolet repair and aging burn bitumen bond. Their analysis showed that $\mathrm{TiO} 2$ using nanowires can affect asphalt bond aging at low speeds and decrease aging. Its effect on the hardness of the asphalt adhesive should be evaluated, since the addition of nanoscale powders is considerably tightening the bonding.

\section{INTRODUCING NANOCLAYAS AN ASPHALT MODIFIER}

Now, we will look at using nanoclay as a modifier of asphalt. What are nanoclay? Nanoclayers are fine particles of layered mineral silicates. One nanometer is one billion meters and 10 nanometers is only one tenth the diameter of a human hair. Roles can be organized into several classes, including montmorillonite, bentonite, kaolinite and a few others. It should be noted that not all nanosheets that are considered as asphalt modifiers are nanosized. Some may have only one dimension that is nanoscale in size, such as platelet thickness of bentonite or montmorillonite. Because of the nanoparticles, the properties of many polymers are enhanced. Nanoclay is used to improve the modulus and tensile strength, flame resistance and thermal and structural properties of many 
materials. Montmorillonite is the most common type of nanoclay used in material applications. Montmorillonite has several properties that make it a great base for nanotech manipulation.

Michigan Technical Research A team at the Technical University of Michigan, led by Professor Janping, has been evaluating the use of nanoclay for asphalt remediation. Your team has worked with several types of nanoclay. According to your doctor, two to four percent of nanoclay (asphalt by weight) is slowly added to the asphalt glue as dry particles. The mixing was performed at $275^{\circ} \mathrm{F}(135$ ${ }^{\circ} \mathrm{C}$ ) using a high shear mixer rotating at 6,000 rpm to produce modified fasteners. The mixing process took about two hours. The modified slurry was tested using Super pave equipment and steps. DSR viscosity, dynamic shear modulus $(\mathrm{G})$ and direct stress values were determined. The results of the experiment showed that the modified adhesives were significantly more viscous and more rigid, indicating a resistance to decay.

Speaking at a 2010 Asphalt Emulsion Manufacturers Association meeting, a senior scientist with Akzo Nobel Asphalt Programs discussed the use of clay-based emulsions. While clay was traditionally used as an emulsifier, it was used in the software to modify the properties of asphalt residues. James said that clay emulsions are a way to make nanocomposites using a relatively cold process. Is. This method is the dispersion of clay (without changing the surface) in water. The hot asphalt is then mixed, forming an emulsion in which each small asphalt particle (10-12 microns) is surrounded by even smaller clay particles. It is done, and the emulsions are stable and easy to control. When the emulsion is dried, the residue forms a mixture of clay and asphalt with significantly altered properties. To provide additional performance, polymer-modified asphalt can be emulsified or latex can be added to the clay-based emulsion. Dr. Peter Zhou, chief research chemist with specialty chemicals Akzo Nobel, has done more with asphalt clay emulsions. Traditional experiments such as penetration point and softening point have also been performed. According to Zhou, modified clay adhesives have a highly rheological property.

Have changed, and have higher temperature viscosities but have relatively unchanging properties at low temperatures. Of these properties, Zhou concludes, "In principle, these adhesive properties should allow for the design of harder coatings with less tendency to ditch in hot air or to find use in surfacefree seals without a track." [36]

Asphalt due to its good viscoelastic properties has long been used as a coating on highways and runways [16]. Bitumen is an organic mixture made up of various chemical compounds. The physical properties and chemical structures of the asphalt will change when exposed to heat, oxygen, and ultraviolet (UV) light, called aging. Therefore ideal asphalt should have both: (1) high relative stiffness at high service temperature (summer) to reduce wear and tear, and (2) increases adhesion between asphalt and aggregates if moisture is present. To eliminate. The nanoparticle composition can be expected to enhance their performance due to their properties such as their surface-to-volume ratio.

\section{ApPlication of NANOTEChNOLOGY IN ASPHALT Field}

It is important to ensure that these programs address genuine questions to enable this technology to enhance the general well-being of people, especially when evaluating civil engineering programs. This section addresses specific applications of nanotechnology in the field of road asphalt. The primary purpose of asphalt is to provide a safe and durable surface on which vehicles can move, while protecting the underlying layers of material in all environmental conditions. Likewise, sidewalks are thus subject to two main types of traffic, traffic and the environment. Although good sidewalks can be built using existing materials and techniques, there are a number of areas where the use of wise nanotechnology techniques can improve the durability and performance of the service provided by asphalt facilities. These include advanced and intelligent materials and material descriptions. This chapter discusses current specific needs that are addressed through these programs.

Nanotechnology focuses on nanoscale materials, while civil engineering infrastructures (especially asphalt) are focused on the large scale. A valid question that is often raised is how nanoscale changes can affect macro-scale properties and behavior, and whether it is possible to scale effects and quantities from nanoscale to macro-scale. It also affects some of the nano-effects that may affect the intrinsic mass of a material, where due to simple problems such as the gravitational effect, the same effect will not be visible on a large scale. Large-scale analysis is included of this topic, which demonstrates the general concern of scaling effects that these effects may be subject to asphalt [20]. 
Nanomaterials in Asphalt Compounds and Functions A small nanoparticle, measured in nanometers (nanometers), is often defined as a particle with at least one dimension less than $100 \mathrm{~nm}$. The physics and chemistry of nano-sized particles are different from those of conventional materials, primarily due to the increase in the surface-to-volume ratio of nanometer-sized grains, cylinders, plates, and due to the quantum-space effects of spacecraft. They can be used in asphalt manufacturing based on the literature review of nanoparticles and nanomaterials.

There are concerns about the use of nanomaterials for their safety for the environment and for humans. These concerns should be specifically addressed in the road pavement arena.

\section{NANo ASPhalt in Cold AREaS}

The possibility of using nano-asphalt in cold areas, adding nanosilver modifiers to bitumen increases the hardness of the asphalt and this increases the tear resistance [19]. The conclusion of the ongoing research was obtained by $\mathrm{Yu}$ et al. [32] and Pollako et al. Indirect tensile strength has also been increased due to the introduction of nanocyclic modifiers, which increases resistance to aging. The elasticity of the modified bitumen is increased at elevated temperatures and the energy loss is reduced as the clay is scattered at the nanoscopic surface [12]. These improvements have increased the durability and shelf life of asphalt, which saves costs for maintenance and repair as well as bitumen work in hot areas, as viscosity has increased. However, there are probably some disadvantages of modified asphalt nanomaterials at low temperatures. Research shows that the fatigue strength of nanosilicon-modified bitumen is lower than that of unmodified bitumen at low temperatures [7]. However, according to a study by your professor and his team at the Technical University of Michigan, nanofluid-modified asphalt testing has recently been made in the United States in cold weather [8].

\section{NANOSILICA Silica}

Nanosilica silica is a versatile compound on earth that is mainly used in industries for the production of silica gels, colloidal silica, foam silica and so on. Nanoparticles silicones are interesting particles because they are used in emerging areas such as medicine and drug delivery [1]. Amorphous nanoseconds are known as nanotubes. Silica nanoparticles have been used in industry to reinforce elastomers as a rheological solution [3] and cement concrete mixtures [25]. Silica nanocomposites have also received scientific attention. The advantage of these nanomaterials lies in their low production cost and high performance characteristics. By adding nanosilica to the base asphalt adhesive, the viscosity values of the nano modified asphalt bonds slightly decreased. The low viscosity of the adhesive indicates that a lower compression temperature or lower energy consumption is achieved during the manufacturing process. Adding nanosilica to the asphalt control improved the recovery ability of the asphalt bond. The low temperature gradient of nano silica modified asphalt adhesive was similar to the control asphalt bond and the stress properties and relaxation capacity of the asphalt bond modified with nano silica were the same as the control asphalt. The anti-aging and cracking performance of nano-silica modified adhesive and asphalt mixtures improved and the decay and anti-shedding properties of nano-silica modified asphalt were also significantly increased. However, the addition of nanosilica to the asphalt binder has no effect on the properties of low bond temperature and asphalt mixtures [33].

\section{CONCLUSiONAND RECOMMENDATIONS}

Adding nanoclay to asphalt typically increases the viscosity of asphalt binders and improves the fatigue resistance of asphalt mixtures. A particular type of montmorillonite nanoclay does not affect the hardness and adhesion of asphalt glue. The use of nano can improve the aging resistance of asphalt mixtures. The advent of nanotechnology and the use of nanoparticles at various stages of pavement have made the asphalt mix strong and smart. In this study, in order to evaluate the effect of nanoparticles on the creep resistance of asphalt mixes and to evaluate the macroscopic effects of nanoparticles, the base of asphalt bond with different percentages of $\mathrm{TiO} 2, \mathrm{Al} 2 \mathrm{O} 3, \mathrm{Fe} 2 \mathrm{O} 3$ and ZnOnano was investigated. The results obtained in this study are as follows The use of nanoparticles increased the softening point, flexibility and ash point and decreased the degree of penetration. As the percentage of nanoparticles increased, the viscosity of the asphalt adhesive also increased. This process gives better adhesion asphalt strength against caries accumulated at high temperatures. At low stress intensity loading (150 kPA), the samples containing $\mathrm{ZnO}$ nanoparticles performed better in 
reducing the potential of the asphalt mixture samples against creep. The creep performance of Al2O3 nanoparticles showed high loading $(300 \mathrm{mAh})$. . In general, all four functional nanoparticles reduce the decay probability of asphalt mixture samples compared to asphalt mixture samples without nanoparticles. . SEM can distribute nanoparticles correctly in the asphalt band using a dispenser to form a homogeneous mixture

Adding nanoclay to asphalt typically increases the viscosity of asphalt binders and improves the fatigue and fatigue resistance of asphalt mixtures. A particular type of montmorillonite nanoclay does not affect the hardness and adhesion of asphalt glue. Using nanoclay can improve the aging resistance of asphalt mixtures.

Polymeric nanocomposites are one of the most exciting materials due to the addition of nanoparticles and nanoscale dispersion. The use of nanoparticles can improve the storage stability of polymer modified asphalts.

In this study, different methods of preparation of modified nano-asphalts are investigated and the effect of nanomaterials on basic asphalt properties and mechanisms is summarized.

\section{REFERENCES}

[1] Barik T.K., Sahu B, Swain V. (2008) Nanosilica-from medicine to pest control Parasitol. Parasitol Res, 103, 253-8.

[2] Bhasin, A., et al., 2009. Intrinsic healing in asphalt binders- Measurement and impact of molecular morphology. In: Proceedings of Sixth international conference on maintenance and rehabilitation of pavements and technological control (MAIREPAV6), Torino, Italy, 105-114.

[3] Chrissafis K., Paraskevopoulos K.M., Papageorgiou G.Z., Bikiaris D.N. (2008) Thermal and dynamic mechanical behavior of bionanocomposites: fumed silica nanoparticles dispersed in poly (vinyl pyrrolidone), chitosan, and poly(vinylalcohol). J Appl Polymer Sci, 110, 1739-49

[4] F.L. Roberts et al., Hot Mix Asphalt Materials, Mixture Design and Construction, second ed., National Center for Asphalt Technology (NCAT), 1996.

[5] Galooyak, S.S., et al., 2010. Rheological properties and storage stability of bitumen/SBS/montmorillonite composites. Construction and Building Materials, 24 (3), 300-307.

[6] Goh, S.W., et al., 2011. Effect of deicing solutions on the tensile strength of micro-or nano-modified asphalt mixture. Construction and Building Materials, 25 (1), 195-200.

[7] Ghile, D., 2006. Effects of nanoclay modification on rheology of bitumen and on performance of asphalt mixtures. Delft: Delft University of Technology.

[8] Ghasemia M., Marandi S.M., Tahmooresi M., Kamali R.J., Taherzade R. (2012). Modification of Stone Matrix Asphalt with Nano-SiO2, J. Basic. Appl. Sci. Res., 2(2), 1338-1344.

[9] J.Y. Yu, L. Wang, X. Zeng, S.P. Wu, B. Li, Polym. Eng. Sci. 47 (2007) 1289e1295.

[10] J.S. Zhang, A.Q. Zhang, M.T. Li, J. Xu, Z.H. Wang, W.J. Yin, H. M. Zhao, Mater. Rev. 19 (2005) 87e90 (in Chinese).

[11] J.A. Shen, Pavement Performance of Asphalt and Asphalt Concrete, China Communication Press, Beijing, 2011 (in Chinese).

[12] Jahromi S., Ghaffarpour, K.A. (2009). Effects of Nanoclay on Rheological Properties of Bitumen Binder. Construction and Building Materials, 23, 2894-2904.

[13] Kelsall, R.W., Hamley, I.W., Geoghegan, M. (2005). Nanoscale Science and Technology. John Wiley and Sons Ltd., Chichester

[14] Khattak, M.J., Khattab, A., Rizvi, H.R., \& Zhang, P. (2012). The impact of carbon nano-fiber modification on asphalt binder rheology. Construction and Building Materials, 30, 257 - 264.

[15] Liao, G.-y., Huang, X., and Ba Sang, D.-z., 2008. Antiultraviolet aging and antithermal-oxygen aging tests of asphalts adapting to environment of Tibetan plateau of China. In: Transportation Research Board 87th annual meeting [CDROM], Washington, DC, USA.

[16] L. Loeber, G. Muller, J. Morel, et al., Fuel 77 (13) (1998) 1443- 1450. [2] J. Lamontagne, P. Dumas, V. Mouillet, et al., Fuel 80 (4) (2001) 483-488.

[17] Lazzara G., Milioto S., (2010) Dispersions of nanosilica in biocompatible copolymers, Polymer Degradation and Stability, 95, 610-617.

[18] Mann, S. (2006). Nanotechnology and Construction, European Nanotechnology Gateway.

[19] Mann, S. (2006). Nanotechnology and Construction, European Nanotechnology Gateway. 
[20] Partl, M.N., Gubler, R., Hugener, M. (2003). Nano-science and-Technology for Asphalt Pavement, In: Proc. 1st Int. Symp. on Nanotechnology in Construction, Paisley, Scotland, 343-355

[21] Masson, J.-F., Leblond, V., Margeson, J.: Bitumen morphologies by phase-detection atomic force microscopy. J. Microscopy 221(1), 17-29 (2006)CrossRefMathSciNetGoogle Scholar

[22] Polacco, G., Kr`iž P., Filippi, S., Stastna, J., Biondi, D., Zanzotto L. (2008). Rheological Properties of Asphalt/SBS/clay Blends, European Polymer Journal, 44, 3512-3521.

[23] Partl, M., Gubler, R., and Hugener, M., 2004. Nano-science andtechnology for asphalt pavements. Special Publication - Royal Society of Chemistry, 292, 343-356.

[24] Partl, M., Gubler, R., and Hugener, M., 2004. Nano-science andtechnology for asphalt pavements. Special Publication - Royal Society of Chemistry, 292, 343-356.

[25] Quercia G. and Brouwers H.J.H. (2010). Application of nano-silica (nS) in concrete mixtures, 8th fib PhD Symposium in Kgs. Lyngby, Denmark, June 20 - 23

[26] Teizer Jochen; Venugopal Manu; Teizer Winfried; and Felkl Jakub. (2012). Nanotechnology and Its Impact on Construction: Bridging the Gap between Researchers and Industry Professionals, Journal of Construction Engineering and Management, 138

[27] Trans Tech Publications, (2012), Switzerland, doi:10.4028/www.scientific.net/AEF.5.259 (2012).

[28] Tanzadeh, J., et al., 2013. Laboratory study on the effect of nano TiO2 on rutting performance of asphalt pavements. Advanced Materials Research, 622, 990-994.

[29] W.J. Steyn, J. Transp. Eng. 135 (2009) 764e772.

[30] X. Wang, J.Y. Yu, L. Wang, J.Z. You, Y.Z. Wang, J. Wuhan Univ. Technol. 29 (2007) 81e83 (in Chinese).

[31] You, Z., 2011. Nanoclay-modified asphalt materials: preparation and characterization. Construction and Building Materials, 25 (2), 1072-1078

[32] Yu, J., Li, B., Zeng, X., Wang, X., Hu, H. (2007a). Preparation and Properties of Montmorillonite Modified Asphalts, Journal of Wuhan University of Technology, 29(9), 65-67.

[33] Yao Hui, You Zhangping, Li Liang, Shi Xianming, Goh Shu Wei, Mills-Beale Julian, Wingard David. (2012 a). Performance of asphalt binder blended with non-modified and polymer-modified nanoclay, Construction and Building Materials, 35, 159-170.

[34] Z.P. You, J. Mills-Beale, J.M. Foley, S. Roy, G.M. Odegard, Q.L. Dai, S.W. Goh, Constr. Build. Mater. 25 (2011) 1072e1078.

[35] http://asphaltmagazine.com/introducing-nanoclay-as-an-asphalt-modifier

[36] http://www.asphaltmagazine.com/news/detail.dot?id=46f2abec-6760-43a6-9691-77d8837ebc01

Citation: Khalil tabatabaei \& farhad tabatabaei "Assessment of Nanomaterials Use in Asphalt", International Journal of Constructive Research in Civil Engineering, 5(4), pp. 6-12. DOI: http://dx. doi.org/10.20431/2454-8693.0504002

Copyright: () 2019 Authors, This is an open-access article distributed under the terms of the Creative Commons Attribution License, which permits unrestricted use, distribution, and reproduction in any medium, provided the original author and source are credited. 